Article

\title{
Participation in Social Media: Studying Explicit and Implicit Forms of Participation in Communicative Social Networks
}

\author{
Mikko Villi ${ }^{1, *}$ and Janne Matikainen ${ }^{2}$ \\ ${ }^{1}$ Department of Communication, University of Jyväskylä, 40014 Jyväskylä, Finland; E-Mail: mikko.villi@jyu.fi \\ ${ }^{2}$ Department of Social Research, University of Helsinki, 00014 Helsinki, Finland; E-Mail: janne.matikainen@helsinki.fi \\ * Corresponding author
}

Submitted: 31 January 2016 | Accepted: 2 May 2016 | Published: 10 October 2016

\begin{abstract}
The diverse forms of participation in social media raise many methodological and ethical issues that should be acknowledged in research. In this paper, participation in social media is studied by utilising the framework of explicit and implicit participation. The focus is on the communicative and communal aspects of social media. The aim of the paper is to promote the reconsideration of what constitutes participation when online users create connections rather than content. The underlying argument is that research on social media and the development of methods should concentrate more on implicit forms of participation.
\end{abstract}

\section{Keywords}

connectivity; ethics; explicit participation; implicit participation; methods; social media

\section{Issue}

This article is part of the issue "Successes and Failures in Studying Social Media: Issues of Methods and Ethics", edited by Epp Lauk and Niina Sormanen (University of Jyväskylä, Finland).

(C) 2016 by the authors; licensee Cogitatio (Lisbon, Portugal). This article is licensed under a Creative Commons Attribution 4.0 International License (CC BY).

\section{Introduction}

Participation in social media is multifaceted and, thus, methodologically challenging. In this paper, we shed light on the complexities of social media research by means of a literature review, building on the theoretical framework of explicit and implicit participation. The review of explicit and implicit participation can provide insights for research and methodology in the context of social media. In particular, we suggest that the review can aid in developing methods for studying implicit participation in social media.

First, it is necessary to examine the general concept of participation in social media. The word 'social' in the term 'social media' implies that these platforms facilitate communal activities. In the same sense, the term 'participatory' emphasises human collaboration (van Dijck, 2013, p. 11). However, all participation is not the same. Participation is an ambiguous concept that can take on many different forms, and it can even be seen as a problematic concept that is often overused and overstretched (Carpentier, 2011, pp. 351-353). One approach is to stress participation as a political-ideological concept that is intrinsically linked to power. Carpentier (2011) claims that participation is deeply embedded within our political realities and that it is therefore the object of long-lasting, intense ideological struggles. Carpentier also considers participation as structurally different from interaction. According to him, interaction remains an important condition of participation, but it cannot be equated with participation. Unlike participation, interaction has no such political meanings because participation entails power dynamics and interaction does not (Matikainen, 2015, p. 43).

Many other views on participation are less political and less occupied with notions of power; therefore, they may be closer to interaction. According to Jenkins (2006), participatory culture contrasts with older notions of passive media spectatorship and consumption. Rather than talking about media producers and con- 
sumers as occupying separate roles, we might see them interacting and collaborating. Jenkins refers to this as convergence culture. From this perspective, participation is associated more with acting together and communicating with each other and less with power, politics and struggle, although these elements still play a role.

The action within interaction is of essence. Former passive audiences turn into active participants and agents of cultural production on the Internet (Schäfer, 2011, p. 10). Thereby, audiences become participants or users. The term 'users' is often used to refer to people who are more or less active online. In this sense, 'users' is a better term than 'audience' to indicate interactive participants in social media. Being an audience only captures one segment of the contemporary media experience because an increasing part of online activity involves 'doing' things, such as messaging, sharing, tweeting, using Facebook, chatting, commenting, editing, posting and uploading (Merrin, 2009, p. 24).

Livingstone (2005) states that 'users' as a term does not work very well either. It is too broad, and it has less to do with communication. Users use computers when engaging online, but they also use, for example, washing powder, which does not have much to do with human interaction, communication or communality. Thus, Livingstone proposes that 'people' would be a good term to describe participants in the realm of social media.

It is important to acknowledge that being a user and being an audience member are not mutually exclusive roles. People can be online users and audience members simultaneously. The roles are not always defined by the level of activity, but the role can also be a question of attitude, i.e. how people themselves consider their positions in social media. In addition, the roles can depend on the platform, i.e. what kind of affordances different online platforms offer for interactivity. However, it is reasonable to question the significance of novel communication technology and platforms for participation in general. The presumption that new networked technologies lead to participation is rather generalising (Terranova, 2004; van Dijck, 2009). Nevertheless, users of 'old media' are often stereotyped as a passive audience, and users of digital, participatory media are equally stereotyped as hyperactive, co-creative people (Olsson, 2010, p. 101).

\section{Explicit and Implicit Participation}

To further examine participation, we will focus on explicit and implicit forms of participation (Schäfer, 2011). From the users' standpoint, explicit participation involves producing media texts and artefacts. Explicit participation has a 'pro' aspect, in the sense that it is about production, produsage and prosumerism and is closely linked with user-generated content (UGC). Explicit participation is also connected to co-creation when consumers are no longer satisfied with their tra- ditional end-user roles, and they want to be involved in creating and developing digital products and services (Ramaswamy \& Gouillart, 2010, pp. 3-6).

In contrast to explicit participation, implicit participation does not involve conscious production. Rather, it often comprises unacknowledged labour or even unconsciously performed labour. Implicit participation shows a trend towards automated user participation because it is channelled through easy-to-use interfaces and the automation of user activity processes (Schäfer, 2011 , pp. 51, 78.). In implicit participation, the behaviour patterns, interests and consumption habits of users are turned into valuable data. For example, implicit participation occurs when a user connects his/her Spotify account with Facebook and information about music consumption is thereafter automatically communicated to his/her Facebook friends (Karppi, 2014, pp. 37,72 ). Connections between users are essential to implicit participation. If UGC represents explicit participation, implicit participation is represented by usergenerated behaviour (UGB) (Netzer, TenenboimWeinblatt, \& Shifman, 2014, p. 625).

Most social media platforms are created to generate data about users for improved information management and targeted advertising (Schäfer, 2011, p. 78). In implicit participation, the actions of users and producers (as in produsage, see Bruns, 2012) do not necessarily blur; instead, the actions of users and information technology blur because the labour is performed by both the information system and the user (Schäfer, 2011, p. 78). An obvious example of this is Facebook. The social media platform connects users and technology (e.g. interface and platform infrastructure) to gather data from users. In this sense, implicit participation is closely related to the concept of connectivity (van Dijck, 2013), which we will return to shortly.

Implicit forms of user activity involve sustaining connections and togetherness rather than producing content. In this sense, implicit participation is connected to the ritual view of communication as defined by Carey (1989). Ritual communication concentrates on relationships between people and serves to maintain communality and community. The ritual view of communication exploits the mutual roots of commonness, communion, community and communication (Carey, 1989). However, many people might object to calling implicit online activities participation, at least in the sense that Carpentier has approached participation.

We adapt Schäfer's classification by replacing the dual construction of participation with a continuum or dimension of participation. Activities such as writing a blog post or contributing to a Wikipedia article lie at the explicit end of the continuum. In contrast, at the implicit end of the continuum, participation is nonproductive from the users' point of view. Popular social media activities, such as sharing and liking content, lie between explicit and implicit participation on the con- 
tinuum; however, in our view, they are closer to implicit participation.

\subsection{Users of Users}

Participatory social media users can be regarded, among others, as consumers, producers, distributors or products. We will now focus on the latter two roles, which represent more-implicit forms of participation on the continuum. First, we will discuss how participation can be regarded as a product or commodity. One well-known view associated with social media is that if you are not paying for it, you are not the customer, you are the product' (Noguera Vivo, Villi, Nyirő, de Blasio, \& Bourdaa, 2013). From this view follows the argument that social media companies are users of users because the users and the data they provide about themselves are the products social media companies use in their business.

Van Dijck (2009, 2013) writes about this in a convincing manner. Many social media companies are less interested in selling paid memberships than they are in customers who do not pay anything for services. In exchange for free services, social media companies require the use of users' data. According to van Dijck (2009, p. 49), a user's role as a data provider is infinitely more important to social media companies than the user's role as a content provider. Personal data are turned into public, observable connections, such as liking something on Facebook. Privacy is the currency in social media.

Users profile themselves, e.g. by liking and using social plugins, while social media companies, which can also be called corporate social media (CSM), sell the resulting data to marketers and advertisers (Gehl, 2015). Likes and social plugins create new forms of connectivity between websites, generating a 'like economy' in which the acts integrate more objects into the social graph and enable social media companies to expand their activities throughout the Internet to monetise connections and data flows outside their own platforms (Gerlitz \& Helmond, 2013; Langlois \& Elmer, 2013 , p. 9). Users willingly and often unknowingly provide important information about their profiles and behaviours to CSM companies (van Dijck, 2009, p. 47). This view is very much in line with Schäfer's conception of implicit participation. It can be argued that social media services are built on a double exploitation of explicit and implicit participation. First, social media companies thrive on the free labour of content creators (Terranova, 2004). Second, they exploit the labour of all site visitors, who generate valuable data about their interests and activities as they like and share content. This more-implicit user participation produces data that are valuable to marketers, who want to know what people are interested in and how those interests link to other interests (Gauntlett, 2011, p. 191).
In other words, in the context of participatory culture, users are a commodity sold by the media as eyeballs to advertisers, in the classic view of Smythe (1977), and also the communal activities of the audience, such as liking or distributing news stories, are a commodity (Fuchs, 2010). Social media users represent a labour power that produces attention to ads as well as data, which then feeds into the production of ads (Fisher, 2015, p. 65). Much of the user work or user labour in social media is associated less with production and more with communication and interaction. This also means that user work is described well by implicit forms of participation.

In relation to implicit participation, the role of connectivity has been emphasised as part of social media logic (van Dijck, 2013). Connectivity refers to how social media companies gather data from users and their connections and then exploit this data for their purposes, e.g. by selling that information to advertisers (van Dijck \& Poell, 2013, p. 8). When engaged in social media, users are positioned within an algorithmic connectivity in which machine processes mine their data, which are then used to affect and engage other users (Karppi, 2014). Users produce a precious resource: connectivity (van Dijck, 2013, p. 16).

The term 'connectedness' is closely related to connectivity and implicit participation. In a sense, connectedness involves social media users connecting with each other in a multitude of ways. Commoditising relationships and connections to turn connectedness into connectivity is the essence of the business undertaken by social media companies (van Dijck, 2013). CSMs are less interested in co-creation or UGC than in users making connections, which yield valuable information about who the users are and what they are interested in (van Dijck \& Nieborg, 2009, pp. 865-866). Accordingly, social media platforms record not only what is being said but also the more broad act of communication itself, including information about the profile of a user sending out a message, the users receiving that message and how users interact with a message by reading, liking and sharing it or not (Langlois \& Elmer, 2013, p. 2).

Importantly, social dynamics on social media platforms depend on the platforms themselves (Gillespie, 2015; Helmond, 2015). Social media platforms have simplified the communication process and expanded potential communicative opportunities, but they have also been built to harness communication in an effort to monetise it (Langlois \& Elmer, 2013, p. 2). Social media platforms are designed to enhance human connections and constant connectivity because smaller friendship networks and less communication would lead to less user data to market (Langlois, 2014, p. 7; Langlois \& Elmer, 2013, p. 10). As Gillespie (2015) notes, 'Platforms matter...The platforms, in their technical design, economic imperatives, regulatory frame- 
works, and public character, have distinct consequences for what users are able to do, and in fact do'.

\subsection{Sharing in User Communities}

The context for connectedness can be labelled a 'user community'. When users in social media regularly communicate among themselves, they can be said to form an actual community; otherwise, impermanent, transient and atomised user structures simply represent a crowd (Bruns, 2012, p. 819). The traditional definition of a community, i.e. a spatially compact set of people with a high frequency of interaction, interconnections and a sense of solidarity, does not always fit well with user communities. Social media services in particular do not necessarily make people feel as if they belong to a community. Instead, social media can host sets of interlinked personal communities built on interpersonal commitments (Gruzd, Wellman, \& Takhteyev, 2011, pp. 1296-1299). One way to illustrate a user community is to view it as connections between personal communities formed around friends, followers and other contacts in social media. Social networking services do not form mutually shared communities; instead, interaction takes place in many interlinked personal communities, such as one's Facebook friends. Overall, connectedness is significantly related to communality.

On the continuum of participation, sharing content can be placed at a position closer to implicit participation than to explicit participation. Sharing in social media involves connectedness and connectivity. Those who share content connect with their peers while also connecting with Facebook, Twitter and Google (van Dijck, 2013, p. 45). In general, the consumption of media content has gone from being an individual activity to one in which consumers have the opportunity to interact with others. In a sense, the consumption of content is a social experience (Villi, 2012, p. 627) and a networked practice (Jenkins, 2006, pp. 244-255). Thus, sharing is becoming central to the way in which people experience media content (Hermida, Fletcher, Korrell, \& Logan, 2012, p. 7), such as when they read news stories recommended by others on Facebook. The word 'sharing' fittingly describes participation in social media at large: sharing can be an act of distribution, communication and consumption (Belk, 2010, p. 730; John, 2013). Sharing involves social exchange on the one hand and distribution and dissemination on the other (Wittel, 2011, pp. 3, 8).

We will now focus on sharing in the context of social media specifically from the viewpoint of userdistributed content (UDC). UDC describes the role of horizontal connections in disseminating media content; users take part in distribution processes by enclosing content with social relations (Villi, 2012; Villi \& Matikainen, 2015). Users make personal referrals and guide their peers to consume content that they consider interesting and relevant by recommending the content on Facebook, tweeting links or sending messages through email or instant messaging applications. UDC involves sharing as a method of distribution. UDC refers to audience activities that serve to amplify the extent, visibility and impact of existing online media content. In this sense, it is possible to draw clear boundaries between UDC and user-generated content (UGC), which clearly involves producing new content.

Terms and concepts that closely relate to UDC include superdistribution, i.e. forwarding media through social networks (Anderson, Bell, \& Shirky, 2013, p. 14), and social curation, which illustrates the networked distribution of media content by adding qualitative judgements and imbuing the content with personal and social significance (Villi, 2012, p. 615; Villi, Moisander, \& Joy, 2012). Singer (2014, p. 68) has coined the term 'usergenerated visibility', which is very close to UDC. The idea of friendcasting (Lee \& Cho, 2011) is implicit in these approaches to social media use. User-copied content (UCC) can also be linked to UDC (van Dijck, 2013, p. 119).

UDC has the advantage of not being a very timeconsuming activity for users. In many ways, UDC represents 'easy participation' (Newman \& Levy, 2013, p. $70)$, consisting of simple, everyday actions (Jenkins, Ford, \& Green, 2013, p. 199) that represent a light version of participation, i.e. 'participation lite'. Using a social plugin, such as pressing the Facebook recommend button placed next to a news item or another story, is less demanding than writing a post. In UDC, personal recommendations by online contacts, especially by friends, are of utmost importance; having media content recommended by a friend is very effective when deciding what content to consume (Enda \& Mitchell, 2013; Matikainen \& Villi, 2013). Influencers-people with large networks of connected followers and friends-are also important (van Dijck, 2013, p. 40). The term 'alpha distributors' can be used to refer to users who act as key nodes in social media and whose recommendations have an extensive reach and influence.

UDC involves connectedness in the sense that it entails communicative interactions and relationships between two or more individuals. At the same time, it represents connectivity because users lure their peers to consume media content, which then leads to data generating audience traffic. Users who distribute content in social media also engage in the work of advertisers and marketers by endorsing brands and their content (Napoli, 2010, p. 512) and mobilising themselves in the promotion of brands (Fisher, 2015, p. 50).

\subsection{Participation and the Media}

Explicit and implicit forms of participation can also be examined in the context of mass media and journalism. 
Until now, UGC has been the most-recognised form of audience participation in journalism (Noguera et al., 2013), and legacy media organisations' strategies concerning audience participation have concentrated largely on UGC (Napoli, 2010; Netzer et al., 2014; Singer et al., 2011). However, an increasing number of media scholars have argued that for legacy media organisations, engaging, encouraging and assisting the audience in the circulation of media content is more important than having them participate in content production (Hermida et al., 2012; Singer et al., 2011). Naturally, these two ideas are interlinked in the sense that content in social media often acts as a social glue that connects people, such as when users view photographs on Instagram.

Marshall (2009) argued that the successful operation of the media industry in social media is as much related to content production as it is to facilitating the maintenance of social connections among its audience. In other words, the work of editorial teams is transformed from content production through creating platform concepts to coordinating, managing and nurturing audience communities (Malmelin \& Villi, 2015).

Jönsson and Örnebring (2011) offer a simple distinction between a) features that require a low level of participation in the media, mainly addressing audience members as consumers; $b$ ) features that require a medium level of participation, addressing audience members as prosumers; and c) features that require a high level of participation, addressing audience members as producers. An example of the low level of participation is the use of the social media audience as a 'radar' (Villi, 2012, p. 616). Within the radar, journalists can observe which stories and content circulate the most in social media and make content decisions accordingly. Another term used to describe journalists watching what users discuss online is 'public sensor' (Heinonen, 2011, pp. 37-38). When users are monitored, the simple act of liking or sharing content can influence decision-making processes in mass media; thereby, users can take part in news selection and gatekeeping (Netzer et al., 2014, p. 628). Moving from a low level to a high level of participation correlates with the transition from implicit to explicit participation.

\subsection{Methodological Challenges of Studying Implicit Participation}

Now, we move on to discussing the methodological challenges of social media research. In connection to the continuum of explicit and implicit participation, a fundamental methodological challenge is the tension between human action and the data-based environment. As van Dijck and Poell (2013) demonstrated, programmability is an essential element of social media logic. Sociality is produced on social media platforms, and their code, data, algorithms, protocols and inter- faces impose preconditions for social interactions and social being. The corpus is not just the product of people's participation; it is also crafted by social media platforms according to the logic of their algorithms, the imperatives of their business models and the enforcement of community guidelines (Gillespie, 2015).

Here, we can again refer to Schäfer's (2011) claim that in implicit participation, a user's actions and information technology are strongly interlinked. Therefore, there is both a human-social aspect and a databased aspect of interaction and participation. When studying implicit participation, both of these aspects should be considered. However, the aspects are methodologically and pragmatically different. In most cases, user data are quantitative, but participation is human and social in nature; the human-social aspect of participation emerges in meanings and discourses.

To understand this context, Lessig (2001) has developed a useful specification. He presents three distinct layers of the Internet. The first layer is the physical layer, which is the basis of communication, i.e. computers and the wires that link computers. The physical layer, i.e. the hardware, enables operations in information networks. The second layer is the code layer, which makes the hardware run. This layer includes protocols and code. The third layer is the content layer, which is the visible part of the Internet, including images, texts and videos. Lessig's specification of the three layers helps us understand that implicit participation and participation in general operate on three levels, and the content layer is the only one visible to users.

In social media, the power of algorithms, i.e. the code layer, is stronger now than it has ever been. As Bucher (2012) notes, algorithmic architectures dynamically constitute certain forms of social practices. For example, Facebook's algorithms are based on the assumption that users are not equally connected to their friends. This assumption has two methodologically important consequences. First, explicit and implicit participation are partly constituted by the algorithm. Second, the data produced by algorithms is relevant when studying participation in social media.

A further methodological challenge involves determining how to gather research data, which in social media could be rather extensive. The data can be either user-based or platform-based, following the continuum from explicit to implicit participation. Traditionally, research data in social sciences have been gathered through surveys, interviews, observations and documentation, which are generally manual methods. Social media and the Internet in general generate a need for new forms of data analysis and software-supported data capture (Rieder, Abdulla, Poell, Woltering, \& Zack, 2015), such as network analysis. For example, Facebook produces diverse, broad data, which can be gathered using computational techniques (Sormanen et al., 2016), such as an application programming interface (API). API- 
based data can highlight the role of administrators as connective leaders, measure the size and composition of the participating audience, engage in various types of periodisation and investigate issues that have been raised in comment sections (Rieder et al., 2015).

Even with new forms of data, interaction and participation in social media cannot be analysed fully using either qualitative or quantitative methods. The relationship between quantitative and qualitative methods is vague because they are based on different assumptions of reality and human action. The challenge is then to combine qualitative and quantitative methods in a sensible way. Quantitative and qualitative data also require various analytical skills, and multidisciplinary research is often necessary. In social media research, the lack of technical skills may lead to limited data and biased analysis (Weller, 2015). In addition, we should not become blinded by new data and methods. Big data and network visualisation can be impressive and imposing, but analytically, they are rather conventional. We as researchers must not only preserve analytical and critical thinking but also remain curious about new data and methods.

The challenge of data access and ownership of user data is of essence to research. As mentioned earlier, social media companies utilise user data as a product in their businesses. Thus, the data are commonly considered trade secrets. This causes many problems from a methodological perspective. At worst, research could be limited only to data that are freely available. This phenomenon is already evident, as shown in the amount of social media research focusing on Twitter due to the platform's comparatively easy and stable data access (Weller, 2015). Another point is that a majority of online participation is increasingly unreachable and hidden from researchers. The popularity of messaging apps, such as WhatsApp (Newman \& Levy, 2014, p. 70), LINE and iMessage, in online communication is growing; however, data from these apps cannot be analysed in the same manner as traffic on Twitter.

\subsection{Ethical Considerations}

When conducting research on social media, ethical aspects should be considered. Implicit and explicit participation especially relate to the question of privacy, which depends on individual and cultural definitions and expectations (Markham \& Buchanan, 2012, p. 6). These definitions are extremely complicated in the context of participation because users do not often perceive on their own whether their participation is implicit or explicit, or do not realise that their activity is participation at all.

As Sveningsson Elm (2009) notes, public and private are not univocal states; instead, they are based on users' perceptions. In this situation, researchers should be sensitive to users' rights and privacy. One essential notion is that like implicit and explicit participation, the concepts of public and private should be considered as a continuum and not a dichotomy (Sveningsson Elm, 2009). Many social media environments are semipublic, where some parts of the environment are public and some parts are not; in these cases, the definition of privacy is ambiguous. As Henderson, Johnson and Auld (2013, p. 550) stated, 'In the context of social media, it becomes increasingly difficult, if not impossible, to ethically claim a dichotomy of private or public'.

An important ethical aspect is the question of consent (Henderson et al., 2013, p. 549). If the research subject is identifiable, consent is needed. However, in the case of social media, from whom should consent be obtained and how should it be obtained? Consent is closely related to the above-mentioned dimension of private and public. Basically, consent is needed when content or communication is private. Because drawing the line between private and public in social media is challenging and sometimes even impossible, researchers should be extremely careful when gathering research data without consent. Often, the difficulty of obtaining consent adds to the challenge.

Research participants or subjects are regularly promised anonymity (Dawson, 2014). In social media, data are diverse because they also include information regarding people's preferences and social relationships, which is often a result of implicit participation. In relation to implicit participation, it should be noted that personal data in social media are also produced by platforms. Platform-based data can often reveal a user's identity easier than when the user makes an explicit decision to reveal or hide his or her identity.

One important question revolves around how researchers can penetrate social media, especially implicit forms of participation. Corporate social media companies are not shy about collecting information on implicit participation, and many users are not aware that they are leaving traces and collectable information. Can researchers be as straightforward and ethically blunt when digging into the forms and practices of implicit participation? How active as participants should the researchers themselves be? In relation to these questions, Markham (2013, p. 440) questions whether participation is always necessary for ethnographers working in online environments.

The ethical challenges are increased by the fact that children and young adults are remarkably active on social media. Scientific ethical rules emphasise that all humans, especially children, should be protected. It is interesting to note that despite many rules and guidelines related to research ethics, there are few empirical studies on ethics in online research (Dawson, 2014). Therefore, we suggest that in addition to concrete, detailed ethical rules concerning social media research, more meta-analysis of the fulfilment of research ethics in social media research is needed. 


\section{Conclusions}

In this paper, we emphasised that implicit and explicit participation are the two ends of the continuum of participation. At the implicit end of the continuum lies fully automatic participation, as exemplified by the programmed publication of music listening habits on Facebook after listening to music on Spotify. At the explicit end lies writing a blog or publishing a picture on Instagram. Sharing and liking lie between the two ends of the spectrum, although they more closely represent implicit participation. Both explicit and implicit participation in social media are motivated at least partly by connectedness, and they benefit and support connectivity. Connectivity represents the relationship between the user and the information system or the platform (such as Facebook and Google), whereas connectedness represents the relationship between users.

We argue that the more-implicit forms of user participation in the communicative social networks of social media are of essence, especially for social media companies that offer services and platforms for interaction and that rely on connectivity in their businesses. We suggest that this is also increasingly the case for legacy media organisations. Therefore, we claim that when attempting to describe the instrumental participatory activities of users in a social media environment, discussion of UGC and other forms of moreexplicit participation should be supplemented with discussion of more-implicit forms of participation. Accordingly, the development of methods should focus more on the study of implicit participation, which has not been the case in previous research.

The continuum of explicit and implicit participation should be considered as a theoretical, methodological, ethical and pragmatic phenomenon. Therefore, the elaboration of theoretical concepts is necessary but insufficient. We should remember that many methodological and pragmatic aspects can restrict the operationalisation of participation in social media and the nature of the data. For example, Langlois and Elmer (2013, pp. 10-11) argue that the promise that social media data offer a transparent trace of human behaviour is false because the behaviour is affected by the corporate logic of social media platforms. This leads to several challenges when studying modes of participatory culture on social media platforms, including access to data, the ethics of data research, the data, and what the data claim to stand for.

\section{Conflict of Interests}

The authors declare no conflict of interests.

\section{References}

Anderson, C. W., Bell, E., \& Shirky, C. (2013). Post- industrial journalism: Adapting to the present. Retrieved from http://towcenter.org/wp-content/up loads/2012/11/TOWCenter-Post_Industrial_Journalis m.pdf

Belk, R. W. (2010). Sharing. Journal of Consumer Research, 36(5), 715-734. doi:10.1086/612649

Bruns, A. (2012). Reconciling community and commerce? Collaboration between produsage communities and commercial operators. Information, Communication \& Society, 15(6), 815-835. doi:10.10 80/1369118X.2012.680482

Bucher, T. (2012). Want to be on the top? Algorithmic power and the threat of invisibility on Facebook. New Media \& Society, 14(7), 1164-1180. doi:10. $1177 / 1461444812440159$

Carey, J. W. (1989). Communication as culture. Essays on media and society. Boston: Unwin Hyman.

Carpentier, N. (2011). Media and participation: A Site of ideological-democratic struggle. Bristol, UK: Intellect.

Dawson, P. (2014). Our anonymous online research participants are not always anonymous: Is this a problem? British Journal of Educational Technology, 45(3), 428-437.

Enda, J., \& Mitchell, A. (2013). Friends and familyImportant drivers of news. The Pew Research Center's Project for Excellence in News Journalism. Retrieved from http://www.stateofthemedia.org/20 13/special-reports-landing-page/friends-and-familyimportant-drivers-of-news

Fisher, E. (2015). "You media": Audiencing as marketing in social media. Media, Culture \& Society, 37(1), 5067. doi:10.1177/0163443714549088

Fuchs, C. (2010). Labor in informational capitalism and on the internet. The Information Society, 26(3), 179196. doi:10.1080/01972241003712215

Gauntlett, D. (2011). Making is connecting: The social meaning of creativity, from DIY and knitting to YouTube and Web 2.0. Polity Press: Cambridge, UK.

Gehl, R. W. (2015). The case for alternative social media. Social Media + Society, 1(2). doi:10.1177/2056305 115604338

Gerlitz, C., \& Helmond, A. (2013). The like economy: Social buttons and the data-intensive web. New Media \& Society, 15(8), 1348-1365. doi:10.1177/14614448 12472322

Gillespie, T. (2015). Platforms Intervene. Social Media + Society, 1(1-2). doi:10.1177/2056305115580479

Gruzd, A., Wellman, B., \& Takhteyev, Y. (2011). Imagining Twitter as an Imagined community. American Behavioral Scientist, 55(10), 1294-1318. doi:10.1177/ 0002764211409378

Heinonen, A. (2011). The journalist's relationship with users: New dimensions to conventional roles. In J. B. Singer, D. Domingo, A. Hermida, A. Heinonen, S. Paulussen, T. Quandt, ... . M. Vujnovic (Eds.), Participatory journalism: Guarding open gates at online newspapers (pp. 34-56). Chichester, UK: Wiley-Blackwell. 
Helmond, A. (2015). The Platformization of the web: Making web data platform ready. Social Media + Society, 1(2). doi:10.1177/2056305115603080

Henderson, M., Johnson, N. F., \& Auld, G. (2013). Silences of ethical practise: Dilemmas for researchers using socila media. Educational Research and Evaluation, 19(6), 546-560.

Hermida, A., Fletcher, F., Korrell, D., \& Logan, D. (2012). Share, like, recommend: Decoding the social media news consumer. Journalism Studies, 13(5-6), 815-824.

Jenkins, H. (2006). Convergence culture. New York: NYU Press.

Jenkins, H., Ford, S., \& Green, J. (2013). Spreadable media: Creating value and meaning in a networked culture. New York: New York University Press.

John, N. A. (2013). The Social logics of sharing. The Communication Review, 16(3), 113-131. doi:10.1080/ 10714421.2013.807119

Jönsson, A. M., \& Örnebring, H. (2011). User-generated content and the news: Empowerment of citizens or interactive illusion? Journalism Practice, 5(2), 127144. doi:10.1080/17512786.2010.501155

Karppi, T. (2014). Disconnect.Me: User engagement and Facebook. Turku: University of Turku.

Langlois, G. (2014). Meaning in the age of social media. New York: Palgrave Macmillan.

Langlois, G., \& Elmer, G. (2013). The research politics of social media platforms. Culture Machine, 14, 1-17.

Lessig, L. (2001). The future of ideas: The fate of the commons in a connected world. New York: Random House.

Livingstone, S. (2005). People living in the new media age: Rethinking "audiences" and "users". In New approaches to research on the social implications of emerging technologies. UK: Oxford Internet Institute.

Markham, A. N. (2013). Fieldwork in Social media what would malinowski do? Qualitative Communication Research, 2(4), 434-446. doi:10.1525/qcr.2013.2.4. 434.434

Markham, A. N., \& Buchanan, E. (2012). Ethical decisionmaking and internet research: Recommendations from the AolR ethics working committee. Retrieved from http://aoir.org/reports/ethics2.pdf

Marshall, D. P. (2009). New media as transformed media industry. In J. Holt \& A. Perren (Eds.), Media industries: History, Theory, and method (pp. 81-89). Chichester, UK: Wiley-Blackwell.

Matikainen, J. (2015). Motivations for content generation in social media. Participations: Journal of Audience \& Reception Studies, 12(1), 41-58.

Merrin, W. (2009). Media Studies 2.0: Upgrading and open-sourcing the discipline. Interactions: Studies in Communication and Culture, 1(1), 17-34. doi:10.138 6/iscc.1.1.17/1

Napoli, P. M. (2010). Revisiting "mass communication" and the "work" of the audience in the new media environment. Media, Culture \& Society, 32(3), 505-

\section{6. doi:10.1177/0163443710361658}

Netzer, Y., Tenenboim-Weinblatt, K., \& Shifman, L. (2014). The construction of participation in news websites: A five-dimensional model. Journalism Studies, 15(5), 619-631. doi:10.1080/1461670X.2014. 895527

Newman, N., \& Levy, D. A. L. (2013). Reuters institute digital news report 2013: Tracking the future of news. Reuters Institute for the Study of Journalism. UK: University of Oxford.

Newman, N., \& Levy, D. A. L. (2014). Reuters institute digital news report 2014: Tracking the future of news. Reuters Institute for the Study of Journalism. UK: University of Oxford.

Noguera Vivo, J. M., Villi, M., Nyirő, N., de Blasio, E., \& Bourdaa, M. (2013). The role of the media industry when participation is a product. In N. Carpentier, $\mathrm{K}$. C. Schrøder, \& L. Hallet (Eds.), Audience Transformations: Shifting audience positions in late modernity (pp. 172-190). New York: Routledge.

Olsson, T. (2010). From the ecology of broadcasting to the ecology of participation critical reflections. Nordicom Review, (2-3), 95-104.

Ramaswamy, V., \& Gouillart, F. (2010). The power of cocreation. New York: Free Press.

Rieder, B., Abdulla, R., Poell, T., Woltering, R., \& Zack, L. (2015). Data critique and analytical opportunities for very large Facebook Pages: Lessons learned from exploring "we are all Khaled Said." Big Data \& Society, 2(2). doi:10.1177/2053951715614980

Schäfer, M. T. (2011). Bastard culture! How user participation transforms cultural production. culture. Amsterdam: Amsterdam University Press.

Singer, J. B. (2014). User-generated visibility: Secondary gatekeeping in a shared media space. New Media \& Society, 16(1), 55-73. doi:10.1177/1461444813477833

Singer, J. B., Domingo, D., Hermida, A., Heinonen, A., Paulussen, S., Quandt, T., . . . Vujnovic, M. (2011). Participatory journalism: Guarding open gates at online newspapers. Chichester, UK: Wiley-Blackwell.

Smythe, D. W. (1977). Communications: Blindspot of Western marxism. Canadian Journal of Political and Social Theory, 1(3), 1-27.

Sormanen, N., Rohila, J., Lauk, E., Uskali, T., Jouhki, J., \& Penttinen, M. (2016). Chances and challenges of computational data gathering and analysis. Digital Journalism, 4(1), 55-74. doi:10.1080/21670811.2015. 1096614

Sveningsson Elm, M. (2009). How do various notions of privacy influence decisions in qualitative Internet research? In A. N. Markham \& N. K. Baym (Eds.), Internet inquiry: Conversations about method. Los Angeles: Sage.

Terranova, T. (2004). Network culture. London: Pluto Press.

van Dijck, J. (2009). Users like you? Theorizing agency in user-generated content. Media, Culture \& Society, 
31(1), 41-58. doi:10.1177/0163443708098245

van Dijck, J. (2013). The culture of connectivity: A critical history of social media. Oxford: Oxford University Press.

van Dijck, J., \& Nieborg, D. (2009). Wikinomics and its discontents: A critical analysis of Web 2.0 business manifestos. New Media \& Society, 11(5), 855-874. doi:10.1177/1461444809105356

van Dijck, J., \& Poell, T. (2013). Understanding social media logic. Media and Communication, 1(1), 2-14. doi:10.12924/mac2013.01010002

Villi, M. (2012). Social curation in audience communities: UDC (User-distributed content) in the networked media ecosystem. Participations: The International Journal of Audience and Reception Studies, 9(2), 614632.
Villi, M., \& Matikainen, J. (2015). Mobile UDC: Online media content distribution among Finnish mobile Internet users. Mobile Media \& Communication, 3(2), 214-229. doi:10.1177/2050157914552156

Villi, M., Moisander, J., \& Joy, A. (2012). Social curation in consumer communities: Consumers as curators of online media content. Advances in Consumer Research, 40, 490-495.

Weller, K. (2015). Accepting the challenges of social media research. Online Information Review, 39(3), 281 289. doi:10.1108/OIR-03-2015-0069

Wittel, A. (2011). Qualities of sharing and their transformations in the digital age. International Review of Information Ethics, 15, 3-8. Retrieved from http://www.i-r-i-e.net/inhalt/015/015-Wittel.pdf

\section{About the Authors}

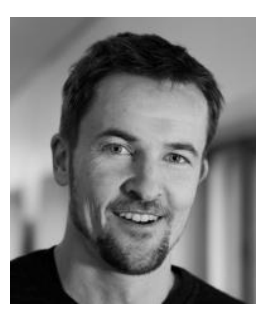

Mikko Villi, Ph.D., is a Professor of Journalism in the Department of Communication at the University of Jyväskylä, Finland. His research and teaching is focused on journalism, media management and media work, concentrating on mobile, visual and social media. His international experience includes working as an international research fellow at the University of Tokyo.

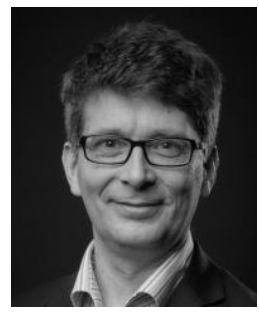

Janne Matikainen, D.Soc.Sc., works as a researcher in Media and Communication Studies in the Department of Social Research at the University of Helsinki. His expertise is concentrated on the social aspects of the Internet. His research focuses on interaction in online communication, online participation and content-generation motives in social media. In recent years, he has studied the relationship between traditional and social media, especially from the audience's perspective. 